\title{
Application of Iridium Catalysts in the Fine Chemicals Industry
}

Hans-Ulrich Blaser

\section{1 \\ Introduction}

Traditionally, catalysis is associated with the production of bulk chemicals, whereas fine and specialty chemicals are produced predominantly with noncatalytic organic synthesis. While these statements are basically still correct, there is a growing list of examples demonstrating that catalytic processes are also an opportunity for the production of more complex agrochemicals and pharmaceuticals [1]. However, our experience shows, that only relatively few catalytic transformations are actually applied on a larger scale and it is probably not surprising that the most important catalytic applications in fine chemicals manufacture are in the area of chemoselective and enantioselective hydrogenation [2,3]. Not surprisingly, this is also the case for the-until now-rather scarce industrial applications of Ir-catalyzed reactions. For this reason, the enantioselective hydrogenation of $\mathrm{C}=\mathrm{N}$ and of nonfunctionalized $\mathrm{C}=\mathrm{C}$ bonds will be discussed in some detail, while miscellaneous catalytic transformations with industrial potential will be summarized only briefly.

\section{2}

\section{Industrial Requirements for Applying Catalysts}

In order to understand the challenges facing the application of catalysts in the fine chemicals industry, one has to understand not only the essential industrial requirements but also how process development is carried out, and which criteria determine the suitability of a catalyst.

\subsection{1}

\section{Characteristics of the Manufacture of Enantiomerically Pure Products}

The manufacture of chiral fine chemicals such as pharmaceuticals or agrochemicals can be characterized as follows (numbers given in parentheses reflect the experience of the authors): 
- Multifunctional molecules produced via multistep syntheses (five to 10 or more steps for pharmaceuticals, and three to seven steps for agrochemicals) with short product lives (often $<20$ years).

- Relatively small-scale products $\left(1-1000 \mathrm{ty}^{-1}\right.$ for pharmaceuticals, 500-10000 ty ${ }^{-1}$ for agrochemicals), usually produced in multipurpose batch equipment [continuous processes are very rare and catalyst recycling is cumbersome, especially under a good manufacturing practice (GMP) regime].

- High-purity requirements (usually $>99 \%$ and $<10 \mathrm{ppm}$ metal residue in pharmaceuticals).

- High added values and therefore tolerant to relative high process costs (especially for very effective, small-scale products).

- Short development time for the production process (less than a few months to 1-2 years), since the time to market affects the profitability of the product and, in addition, development costs for a specific compound must be kept low as process development starts at an early phase when the chance of the product to ever 'make it' is about $10 \%$.

- At least in European companies, chemical development is carried out by allround organic chemists, sometimes in collaboration with technology specialists. For this reason, catalysts must be available commercially as there is little expertise (and time) for making complex catalysts.

\subsection{2}

\section{Process Development: Critical Factors for the Application of Catalysts}

It is useful to divide the development of a manufacturing process into different phases:

Phase 1: Outlining and assessing possible synthetic routes on paper. Here, the decision is made whether to use chemocatalytic steps for making the desired product or to use classical organic synthesis. This decision will depend on a number of considerations, such as the goal of the development, the knowhow of the investigators, the time frame, or the available manpower and equipment.

Phase 2: Demonstrating the chemical feasibility of the key step-which often is the catalytic reaction-and showing that the catalytic step fits into the overall synthetic scheme.

Phase 3: Optimizing the key catalytic reaction as well as the other steps. Showing the technical feasibility (catalyst separation, metal impurities, etc.)

In Phases 2 and 3, it is not only the results of the catalyst tests (selectivity, activity, productivity, catalyst costs, etc.) but also the total product costs that decide whether the catalytic route will be further developed, or abandoned. 
Phase 4: Optimizing and scale-up of the catalytic step as well as of the overall process.

In the final analysis, the choice as to whether a synthesis with an catalytic step is selected depends very often on the answers to two questions:

- Can the costs for the overall manufacturing process compete with alternative routes?

- Can the catalytic step be developed in the given time frame?

\subsection{3}

\section{Requirements for Practically Useful Catalysts}

Based on the published results and our own experience, we consider that several requirements should be met in order to make catalysts feasible for industrial applications.

\subsubsection{Preparation Methods}

It is not really possible to predict what type of catalyst will be suitable for a given substrate and process. Therefore, flexible methods that allow different combinations of the most important catalyst components such as metal, ligand or support are vitally important.

\subsubsection{Catalysts Cost}

The catalyst costs will only be important later, when the costs of goods of the desired product are compared. For homogeneous catalysts, the (chiral) ligand often is the most expensive component (typical prices for the most important chiral phosphines are 100 to $500 \$ \mathrm{~g}^{-1}$ for laboratory quantities and 5000 to $>40000 \$ \mathrm{~kg}^{-1}$ on a larger scale).

\subsubsection{Availability of the Catalysts}

If a specific catalyst is not available at the right time, and in the appropriate quantity, it will not be applied due to time limitations for process development. Today, a sizable number of homogeneous catalysts and ligands (especially for hydrogenation) are available commercially in technical quantities.

\subsubsection{Catalytic Performance}

The performance concerning selectivity, activity, productivity and so on, must fulfill the requirements of a given product. As a rule of thumb, (enantio)selectivity should be $>90-95 \%$; turnover numbers (TON) should be $>200$ for small volume products and reactions with high added value and $>10000$ for large-volume products; and reaction times should not exceed 5-10 h. Furthermore, functional group tolerance will often be important as most substrates will have other functional groups which can either be reduced or which can interfere with the catalyst via complexation. 


\subsubsection{Separation}

Although the separation of homogeneous catalysts can be problematic, in many cases product distillation or crystallization and sometimes extraction is possible. Trace metals can also be problematic as the limit for metal contamination in biologically active compounds is in the ppm region. An additional purification step such as adsorption is sometimes required.

\section{3}

\section{Enantioselective Hydrogenation of $\mathrm{C}=\mathrm{N}$ Bonds}

\subsection{1}

\section{Catalysts and Scope}

Even though the asymmetric hydrogenation of $\mathrm{C}=\mathrm{N}$ has been investigated less systematically than that of $\mathrm{C}=\mathrm{C}$ and $\mathrm{C}=\mathrm{O}$ groups, the topic is of relevance here as chiral amines are important intermediates for biologically active compounds. The successful implementation of a large-scale process to produce the herbicide (S)-metolachlor, catalyzed by an Ir-josiphos catalyst (see below), has motivated increased efforts. As a consequence, in recent years a variety of catalytic systems has been described for the enantioselective hydrogenation of various $\mathrm{C}=\mathrm{N}$ functions [4]. Ir-based catalysts have been shown to be very effective for the hydrogenation of $\mathrm{N}$-aryl amines, selected endocyclic $\mathrm{C}=\mathrm{N}$ bonds and of quinolines; a summary of the most important results reported up to September 2007 is provided in Table 1.1. It must be pointed out that, with very few exceptions, all results have been obtained with monofunctional model substrates (see Figure 1.1) and optimization was focused on enantioselectivity. As a consequence, the turnover number (TON) and turnover frequency (TOF) of most catalysts are (as yet) insufficient for industrial applications, and only time will tell whether real world substrates can be hydrogenated with the same high enantioselectivities.

Table 1.1 The state of the art for the Ir catalyzed reduction of various $\mathrm{C}=\mathrm{N}$ groups.

\begin{tabular}{|c|c|c|c|c|}
\hline Substrate & ee $(\%)^{a}$ & $\operatorname{TON}^{a}$ & $\operatorname{TOF}\left(\mathbf{h}^{-1}\right)^{a}$ & Ligands $^{b}$ \\
\hline $\mathrm{N}$-Aryl imines & $90->99$ & $100-200$ & $2-50$ & $\begin{array}{l}t \text {-Bu-bis-P* }[5], \text { f-binaphane }[6], \\
1[7], 2[8], 3[9], \text { josiphos [10], } 4[11]\end{array}$ \\
\hline $\begin{array}{l}\text { Endocyclic } \\
\text { imines }\end{array}$ & $86-95$ & $100-1000$ & $2-300$ & $\begin{array}{l}\text { binap }[12,13] \text {, bicp [14], josiphos } \\
\text { [10], bcpm [15] }\end{array}$ \\
\hline Quinolines & $85-97$ & $100-1000$ & $5-80$ & $\begin{array}{l}5 \text { [16], MeO-biphep [17], } 6 \text { [18], } \\
\text { P-phos [19], H8-binapo [20], } \\
7 \text { [21] }\end{array}$ \\
\hline
\end{tabular}

a Typical range for suitable substrate (Figure 1.1) and optimized catalyst.

b For structures, see Figure 1.2. 
<smiles>[2H]C(C)=NBr</smiles>

$\mathrm{N}$-aryl imines<smiles>[R]C1=NCCC2C=[Z]3C#CC12C=C(C)C3(C)C</smiles>

endocyclic imines<smiles>[R]c1ccc2nc(P)ccc2c1</smiles>

quinolines

Figure 1.1 Structure of model substrates.<smiles>OC(c1ccccn1)C1CC2CCC(C1)C2(O)c1ccccc1</smiles>

1<smiles>CC(C)C(O)S(=Nc1ccccc1-c1ccccc1)c1ccccc1</smiles>

2

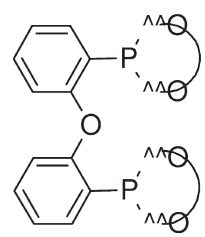

5<smiles>Pc1ccccc1</smiles>

bcpm<smiles>Oc1ccc2ccccc2c1-c1c(O)ccc2ccccc12</smiles>

bicp

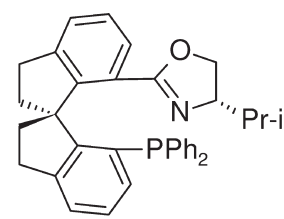

3

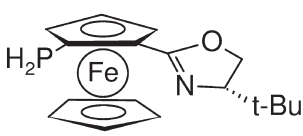

6<smiles>OPOc1ccc2ccccc2c1-c1c(OP(O)O)ccc2ccccc12</smiles>

4<smiles></smiles>

7

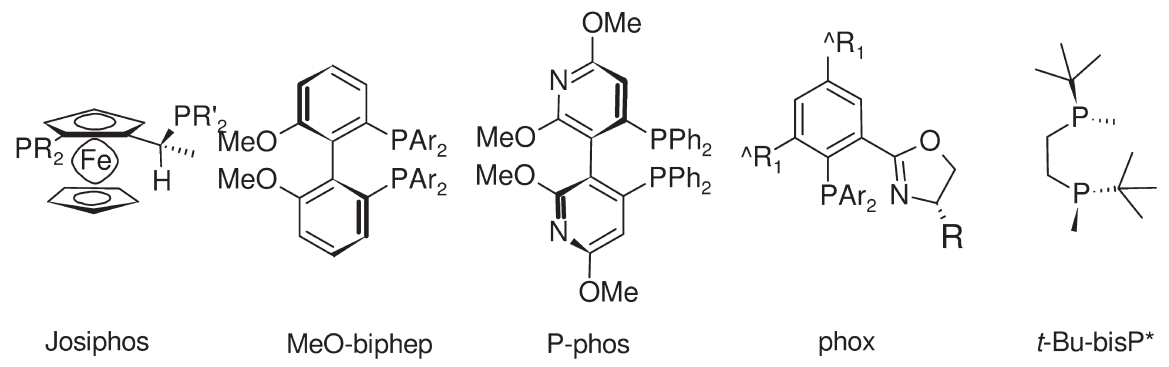

Figure 1.2 Structures of important ligands for the hydrogenation of $C=N$ functions.

Here, a few comments should be made with regards to Table 1.1. It is clear that for all three substrate classes, enantioselectivities can range from good to very high, whereas the TON-and especially TOF-values are less impressive (and in most cases have not been optimized). Most catalyst systems require pressures of 20-100 bar $\left(2-10 \times 10^{4} \mathrm{hPa}\right)$ to achieve realistic reaction times but, as a rule, the chemical yields are very high. In the presence of $\mathrm{Ti}(\mathrm{OiPr})_{4}, \mathrm{Ir} / \mathrm{f}$-binaphane 
catalyzes the reductive amination of aromatic ketones with a variety of substituted anilines with high enantiomeric excess (ee) values but relatively low catalyst activity [6]. It was also shown that Ir-phox catalysts work well in supercritical carbon dioxide $\left(\mathrm{sCO}_{2}\right)$-ionic liquid systems, allowing easy separation and recycling of the catalyst with good catalyst performance [22]. Although the hydrogenation of substituted heteroaromatic substrates provides access to a variety of cyclic amines, this is a very demanding reaction for any homogeneous catalyst, and very few substrate types have been hydrogenated successfully. A patent described the Irjosiphos catalyzed hydrogenation of a pyrazine amide with up to $77 \%$ ee but very low catalyst activity (TON $\sim 20$, TOF $1 \mathrm{~h}^{-1}$ ) [23]. On the other hand, very impressive results were reported for the Ir-catalyzed hydrogenation of various substituted quinoline derivatives, again at high pressures.

\subsection{2}

\section{Industrial Applications}

Until now, only a small number of industrial applications has been reported. The metolachlor process was originally was developed in the Central Research Laboratories of Ciba-Geigy (now Solvias), but is now operated by Syngenta. With a volume of $>10000 \mathrm{ty}^{-1}$ it is the largest known enantioselective catalytic production process [24-26].

Metolachlor is the active ingredient of Dual ${ }^{\mathrm{TM}}$, one of the most important grass herbicides for use in maize and a number of other crops. In 1997, after years of intensive research, Dual Magnum ${ }^{\mathrm{TM}}$, with a content of approximately $90 \%\left(1^{\prime} S\right)$ diastereomers and with the same biological effect at about $65 \%$ of the use rate, was introduced into the market. This 'chiral switch' was made possible by the new technical process that is briefly described below. The key step of this new synthesis is the enantioselective hydrogenation of the isolated MEA imine, as depicted in Figure 1.3.

The search for a commercially viable process took many years, during which time several approaches with $\mathrm{Rh}$ or Ir complexes using commercially available diphosphine ligands proved to be unsuccessful. However, a critical breakthrough was achieved when Ir complexes with a new class of ferrocenyl based ligands - now known as Solvias Josiphos-were used. Especially in the presence of acid and iodide ions, extremely active and productive catalysts were obtained, and conse-

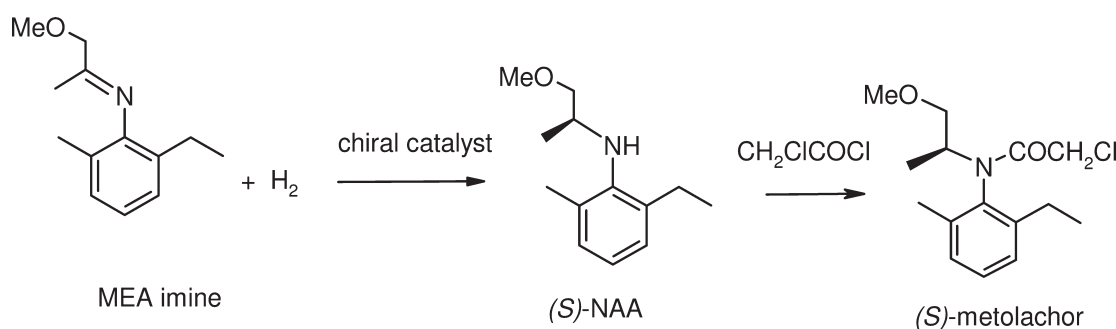

Figure 1.3 Enantioselective synthesis of $(S)$-metolachlor. 
Table 1.2 The most successful Josiphos ligands for the hydrogenation of MEA imine (for ligand structures, see Figure 1.2).

\begin{tabular}{llrrll}
\hline $\mathbf{R}$ & $\mathbf{R}^{\prime}$ & TON & TOF $\left(\mathbf{h}^{-1}\right)$ & ee $(\%)$ & Comments \\
\hline $\mathrm{Ph}$ & $3,5-x y l y l$ & 1000000 & $>300000$ & 79 & Production process \\
$p-\mathrm{CF}_{3} \mathrm{Ph}$ & $3,5-\mathrm{xylyl}$ & 800 & 400 & 82 & Ligand screening \\
$\mathrm{Ph}$ & $4-t \mathrm{Bu}-\mathrm{C}_{6} \mathrm{H}_{4}$ & 5000 & 80 & 87 & Low temperature \\
$\mathrm{Ph}$ & $4-(n-\mathrm{Pr})_{2} \mathrm{~N}-3,5-\mathrm{xyl}$ & 100000 & 28000 & 83 & Optimized conditions \\
\hline
\end{tabular}

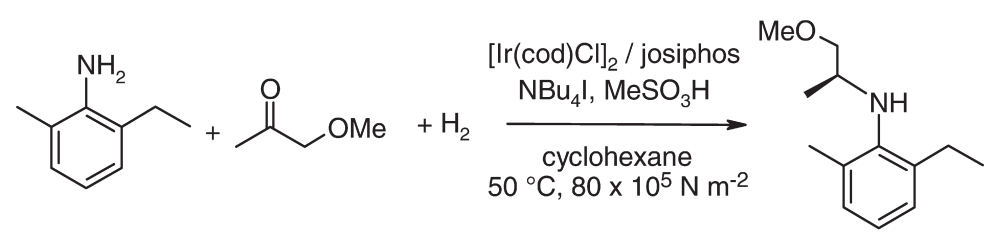

reductive amination $\quad$ ee $78 \%$; TON 10000 ; TOF $>600 \mathrm{~h}^{-1}$

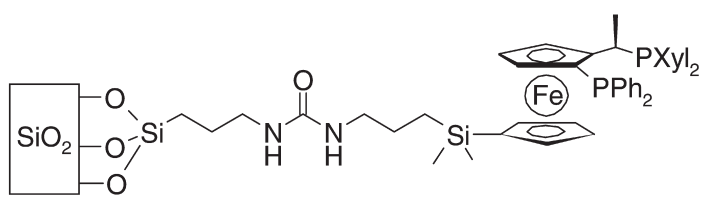

$\mathrm{SiO}_{2}$-bound Josiphos $\quad$ ee $78 \%$; TON 120 000; TOF $12000 \mathrm{~h}^{-1}$

Figure 1.4 Alternative variants for the production of $(S)$-metolachlor.

quently several different Josiphos ligands were tested. A selection of the best results obtained is provided in Table 1.2.

The optimized process is carried out in a loop reactor at $80 \mathrm{bar}\left(8 \times 10^{4} \mathrm{hPa}\right)$ hydrogen and $50^{\circ} \mathrm{C}$ with a catalyst generated in situ from $[\operatorname{Ir}(\operatorname{cod}) \mathrm{Cl}]_{2}$ and the Josiphos ligand $\mathrm{R}=\mathrm{Ph}, \mathrm{R}^{\prime}=\mathrm{Xyl}$ at a substrate-to-catalyst ratio of $>1000000$ in the presence of trace amounts of HI. Complete conversion is reached within 3-4h, the initial TOFs exceed $1800000 \mathrm{~h}^{-1}$, and the ee-value is about $80 \%$. The product (S)-NAA is distilled and the catalyst discarded. Today, this process is operated by Syngenta on a scale of $>10000 \mathrm{ty}^{-1}$.

Two alternatives to the homogeneous hydrogenation of the isolated MEA imine have been investigated (see Figure 1.4). The first method involved the direct amination of MEA with methoxyacetone in order to avoid isolation of the MEA imine [27]; the second method involved the use of immobilized josiphos ligands in order to avoid product distillation [28]. While both variants led to the desired product with similar ee-values as the homogeneous process, both the TON and TOF were insufficient for a technical application.

An Ir-catalyzed hydrogenation developed by Lonza for an intermediate of dextromethorphan was carried out on $>100 \mathrm{~kg}$ scale [29]. Here, the important success factors were the ligand fine tuning and the use of a biphasic system. The 
<smiles>COc1ccc(CC2=NCCC3=C2CCCC3)cc1</smiles>

Ir / Josiphos

$20^{\circ} \mathrm{C}, 70 \times 10^{5} \mathrm{~N} \mathrm{~m}^{-2}$ ee $90 \%$; TON 1500; TOF n.a. pilot process, Solvias/Lonza

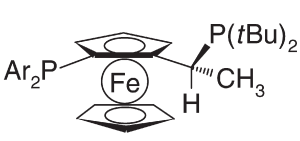<smiles>CC1=Nc2ccc(F)c(F)c2OC1</smiles><smiles>CC(C)(C)C(=O)N1CC(P)CC1CP</smiles>

$\mathrm{Ir} / \mathrm{bppm} / \mathrm{Bil}_{3}$ Josiphos $\mathrm{Ar}=3,5-\mathrm{Me}_{2}-4-\mathrm{OMe}-\mathrm{Ph}$ $-10{ }^{\circ} \mathrm{C}, 40 \times 10^{5} \mathrm{~N} \mathrm{~m}^{-2}$ ee $90 \%$; TON 100; TOF $\sim 30 \mathrm{~h}^{-1}$ feasibility study, Daiichi

Figure 1.5 Industrial hydrogenation of various $\mathrm{C}=\mathrm{N}$ bonds.

chemoselectivity was high but catalyst productivity rather low for an economical technical application. Satoh et al. reported up to $90 \%$ ee for the hydrogenation of an intermediate of the antibiotic levofloxacin using Ir-diphosphine complexes. Best results were obtained with bppm and modified diop ligands in the presence of bismuth iodide at low temperature [30] (Figure 1.5).

\section{4}

\section{Enantioselective Hydrogenation of $\mathrm{C}=\mathrm{C}$ Bonds}

\subsection{1}

\section{Catalysts and Scope}

Generally, the enantioselective hydrogenation of $\mathrm{C}=\mathrm{C}$ bonds is the domain of $\mathrm{Rh}$ and $\mathrm{Ru}$ catalysts $[3,31]$. Whilst this is due to the high effectiveness of these catalysts, it is still somewhat surprising as one of the most active catalysts for hindered $\mathrm{C}=\mathrm{C}$ bonds is Crabtree's $\left[\operatorname{Ir}(\operatorname{cod})\left(\mathrm{PCy}_{3}(\mathrm{py})\right] \mathrm{PF}_{6}\right.$ catalyst [32]. The very remarkable exception is the hydrogenation of alkenes without 'privileged' functional groups, which is much more difficult. Here, Ir catalysts are clearly superior, especially in presence of a variety of $\mathrm{P}, \mathrm{N}$ ligands such as the above-mentioned phox ligands, originally developed by Pfaltz $[33,34]$ which, for the first time, gave high enantioselectivities for unfunctionalized $\mathrm{C}=\mathrm{C}$ (see Figure 1.6) as well as for cyclic analogues. Later, Burgess reported a carbene/N ligand 9 that was similarly effective [35]. Today, a range of ligands exists which with can hydrogenate what Burgess refers to as 'largely unfunctionalized alkenes' with enantioselectivities $>99 \%$. Most catalysts require pressures of $5-50$ bar $\left(0.5-5 \times 10^{4} \mathrm{hPa}\right)$ and, with few exceptions, the TON (typically 50-200) and TOF (typically $10-100 \mathrm{~h}^{-1}$ ) of most catalysts are relatively low. Pfaltz has shown however that, under optimized conditions, a TON of up to 5000 can be realized and that the reactions are initially very rapid, although catalyst deactivation may be problematic. One special feature of these Ir/PN catalysts is their high sensitivity to anions (by far the best results are obtained with [Ir(ligand)(cod)]BARF complexes) and to protic and polar solvents. The very high activity of the selected Ir/PN system was confirmed with the effective hydrogenation of tetrasubstituted $\mathrm{C}=\mathrm{C}$ bonds as well as (benzo)furanes (Figure 1.6), with 


\section{unfunctionalized alkenes}

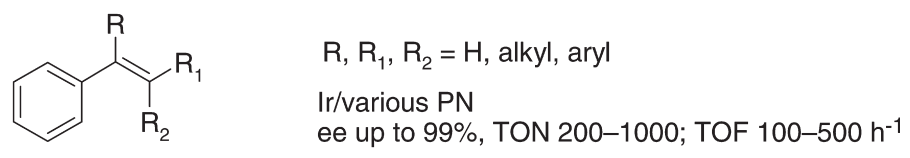

"largely unfunctionalized alkenes"<smiles>[X]C=C(C)c1ccccc1</smiles>

$\mathrm{X}=\mathrm{COOEt}, \mathrm{CH}_{2} \mathrm{OH}$,<smiles>[Y]c1ccccc1</smiles>
$\mathrm{Y}=\mathrm{N}, \mathrm{O}, \mathrm{S}$

Ir/threphox, simplephox ee $94-99 \%$, TON 100 , TOF $\sim 50 \mathrm{~h}^{-1}$

\section{furanes and benzofuranes}<smiles>[R]1cc2ccccc2o1</smiles>

$$
\begin{aligned}
& \mathrm{R}=\mathrm{Me}, \mathrm{COOEt}, \mathrm{CH}_{2} \mathrm{CH}_{2} \mathrm{COOEt} \\
& \text { Ir/8 ee } 92->99 \% \text {, TON } 50-100 \text {, TOF } 2-4 \mathrm{~h}^{-1}
\end{aligned}
$$

Figure 1.6 Hydrogenation of olefins without privileged substitution and of (benzo)furanes.

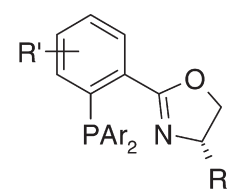

phox<smiles>POC1CCCc2ccc(-c3ccccc3)nc21</smiles>

8<smiles>[R]C1=N[C@H](C([R])([R])OP)[C@H](C)O1</smiles>

threphox<smiles>CCCN1C=CN(CC[C@@H]2COC(C)=N2)C1</smiles>

9<smiles>[R8]C1N=C(C([R])(P)OP)CO1</smiles>

simplephox<smiles>Pc1ccccc1</smiles>

10

Figure 1.7 Selected PN ligands.

very high enantioselectivities and decent TONs. Although purely alkyl-substituted olefins are still difficult substrates, Ir catalysts with selected PN ligands (e.g. 8) have recently been identified that perform well in this case. As this would be beyond the scope of this chapter, at this point we simply depict some of the most effective ligands (see Figure 1.7) and refer the reader to reviews by Pfaltz [34] (phox, threphox, simplephox, 8), Burgess [35] (ligand 9) and Andersson [36] (ligand 10).

\section{4 .2}

\section{Industrial Applications}

Although no large-scale Ir-catalyzed $\mathrm{C}=\mathrm{C}$ hydrogenation processes have yet been reported, two interesting cases indicate their industrial potential. Yue and Nugent 


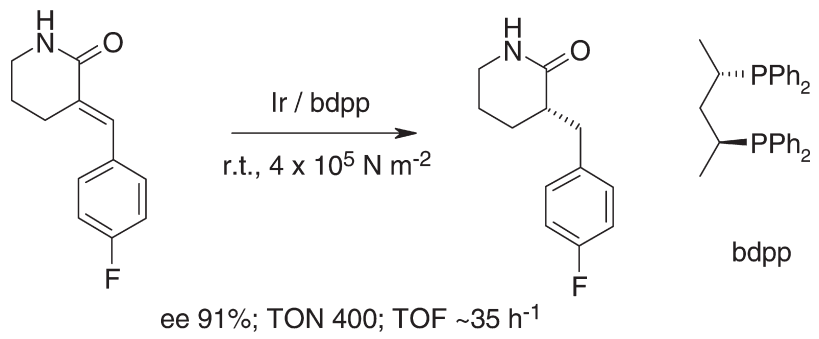

Figure 1.8 Hydrogenation of an $\alpha, \beta$-unsaturated lactam.

[37], at Bristol-Meyers Squibb, described the hydrogenation of an exocyclic $\alpha, \beta$ unsaturated lactam which could be carried out with an Ir/bdpp catalyst with up to $91 \%$ ee (Figure 1.8). The catalyst-which was selected after an intensive screening-involving 32 chiral phosphines and eight $\mathrm{Ru}$, $\mathrm{Rh}$ and Ir precursor complexes. The process was carried out on a $20-\mathrm{kg}$ scale but, presumably, the TON and TOF were too low for consideration as a manufacturing process.

The power of the Ir/PN catalysts was demonstrated in a feasibility study carried out by Pfaltz in collaboration with DSM for the hydrogenation of $\gamma$-tocotrienyl acetate (Figure 1.9) [38]. This reaction involves the reduction of three $\mathrm{C}=\mathrm{C}$ bonds and creates two new stereocenters in a single step. Because the two prochiral $\mathrm{C}=\mathrm{C}$ units are both $E$-configured, the sense of asymmetric induction at the two reaction sites is expected to be the same. The best stereoselectivity was achieved with $\operatorname{Ir} / 8$ $(\mathrm{R}=2$-Tol), which gave almost exclusively the natural $(R R R)$-isomer of $\gamma$-tocopheryl acetate, generating two stereogenic centers in a single step with virtually perfect stereocontrol. Because these catalysts do not require the presence of any particular directing substituents near the $\mathrm{C}=\mathrm{C}$ bond, they should be applicable to a much wider range of olefins than $\mathrm{Rh}$ or Ru catalysts. This was actually confirmed by the hydrogenation of the four stereoisomers of farnesol, where all four stereoisomers of the product were accessible with $\geq 99 \%$ enantioselectivity using the same catalyst but starting from the corresponding $E$ or $Z \mathrm{C}=\mathrm{C}$ bond leading to $R$ and $S$ configuration, respectively [34].

\section{5}

\section{Miscellaneous Catalytic Applications with Industrial Potential}

Besides the reaction discussed above, several Ir-catalyzed reactions are available which probably have some potential to be applied in industrial syntheses.

Asymmetric allylic substitutions are widely applied in organic synthesis, using various metal complexes, chiral ligands, nucleophiles and allyl systems [39]. Although Pd is often the metal of choice, this is not the case for monosubstituted allylic substrates, where most Pd catalysts predominantly produce the achiral linear product. In contrast, Mo, W and Ir catalysts preferentially give rise to the desired branched products and, in recent years, a number of very effective Ir catalysts for various substrates have been developed [40]. Since, to the best of our 


\section{$\gamma$-tocotrienyl acetate}<smiles>[R]c1c(OC(C)=O)cc2c(c1C)O[C@](C)(CCC[C@H](C)CCC[C@H](C)CCCC(C)C)CC2</smiles>

$>98 \%$ conversion, $>98 \% R R R(<0.5 \% R R S, R S R$ or $R S S)$

farnesol

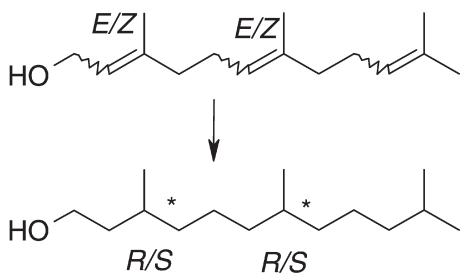

$>99 \%$ conversion, $99 \%$ ee for each stereoisomer

\section{reaction conditions}

$1 \%[\operatorname{lr}(8)(\mathrm{cod})] \mathrm{BARF}$
$\mathrm{CH}_{2} \mathrm{Cl}_{2}, 50 \times 10^{5} \mathrm{~N} \mathrm{~m}^{-2}, \mathrm{rt}, 2 \mathrm{~h}$<smiles></smiles>

Figure 1.9 Hydrogenation of $\gamma$-tocotrienyl acetate and farnesol.

knowledge, no industrial application has yet been described, we provide only a brief summary at this point (see Figure 1.10). While the first results have been obtained with Ir/phox catalysts, phosphorous amidites are the ligands of choice for reactions with malonates (and related compounds), aliphatic nitro compounds, ketone enolates, various N-nucleophiles (amines, sulfonyl- and acylamines), phenolates and Cu-alcoholates. Reactions are usually carried out in the presence of $\left[\operatorname{Ir}(\operatorname{cod}) \mathrm{Cl}_{2}\right.$ and 2 equivalents of ligand $(\mathrm{Ir} / \mathrm{L}=1)$ at about room temperature and with rather low substrate-to-catalyst ratios of between 5 and 50 . The yields are generally good to high, with branched products often $>90 \%$ and ee-values of typically $90-97 \%$. The TOFs vary between 5 and $10 \mathrm{~h}^{-1}$. Pybox (8-12\%), under similar conditions, is preferred for the $\mathrm{N}$-allylation with hydroxylamines, and $\mathrm{O}-$ allylation with hydroxylamines and oximes. Yields vary between 70 and 95\%, typically with 70-95\% branched and ee-values of 80-95\%. The high enantioselectivities obtained with various model compounds indicate considerable synthetic potential, even though the TON and TOF are still rather low. 


\section{effective ligands}<smiles>COP(Oc1ccc2ccccc2c1-c1c(O)ccc2ccccc12)N(C(C)Br)C(C)Br</smiles>

phosphorous amidites<smiles>c1ccc(C2COC(c3cccc(C4=NC(c5ccccc5)CO4)n3)=N2)cc1</smiles>

pybox

allylic substrates

$$
\mathrm{R}=\mathrm{Ar} \text {, Alk } \mathrm{X}=\mathrm{OAc}, \mathrm{OCO}_{2} \mathrm{R}, \mathrm{OP}(\mathrm{O})(\mathrm{OR})_{2}
$$

Figure 1.10 Ligands and allylic substrates for Ir-catalyzed allylic substitution reactions.

\begin{tabular}{lll} 
Catalyst & Yield (\%) & Yield (\%) \\
\hline $\mathrm{Pt} / \mathrm{C}$ & n.a. & 96.0 \\
$\mathrm{Pd} / \mathrm{C}$ & 98.2 & n.a. \\
$\mathrm{Ir} / \mathrm{C}$ & n.a. & $>98.5$ \\
$\mathrm{Ir}-\mathrm{Fe}-\mathrm{Cu} / \mathrm{C}$ & n.a. & $>99.3$ \\
$\mathrm{Ir}-\mathrm{Fe}-\mathrm{Co} / \mathrm{C}$ & 99.4 & n.a.
\end{tabular}

Figure 1.11 Hydrogenation of nitroarenes with $\mathrm{Ir} / \mathrm{C}$ catalysts.

Ir-diphosphine complexes have been shown to catalyze a number of potentially interesting $\mathrm{C}-\mathrm{C}$ coupling reactions [41]. Special mention should be made of the various transformations of alkynes (cycloaddition, isomerization, dimerization, alkynylation), selected aldol and carbonylation reactions, even though the synthetic potential of some of these reactions has not been explored.

Although the focus of this chapter is on homogeneous Ir catalysis, it would be advantageous at this point briefly to describe the unusual selectivity of a number of heterogeneous Ir/C catalysts developed by Degussa for the chemoselective hydrogenation of chloro nitroarenes [42] and dinitrotoluene [43] (Figure 1.11). The results obtained for 2,4-dinitrotoluene and the rather demanding substrate 2,4,5trichloronitrobenzene, show that especially Ir (5\%) catalysts doped with $0.15 \%$ of $\mathrm{Fe}$ and $\mathrm{Cu}$ or $\mathrm{Co}$ are inherently more selective than the Pd and Pt catalysts classically used for these substrates. Both, the selectivity with respect to hydrodechlorination and the formation of byproducts (such as tars in the case of dinitrotoluene) were significantly decreased. These catalysts are commercially available from Degussa and have been applied to unspecified industrial problems on a development scale (D. Ostgard, Degussa, personal communication). 
Besides preparative applications, Ir complexes such as $\operatorname{Ir}(\operatorname{cod})(\mathrm{acac})$ or $\left[\mathrm{cp} * \operatorname{Ir}\left(\mathrm{PMe}_{3}\right) \mathrm{H}_{3}\right] \mathrm{OTf}$ have successfully been applied for hydrogen/deuterium $(\mathrm{H} /$ D) exchange reactions, which are important for producing labeled compounds for kinetic and metabolic studies in the pharmaceutical industries [44]. While we do not know of any 'real world' applications, it has been shown that both selective as well as extensive deuteration are possible, depending on the Ir catalyst and the deuterating agent.

\section{6}

\section{Conclusions and Outlook}

To date, only a few iridium catalysts have been applied to industrially relevant targets, especially on the larger scale. It is likely that several types of Ir catalyst are, in principle, feasible for technical applications in the pharmaceutical and agrochemical industries. At present, the most important problems are the relatively low catalytic activities of many highly selective systems and the fact, that relatively few catalysts have been applied to multifunctional substrates. For this reason, the scope and limitations of most catalysts known today have not yet been explored. For those in academic research, the lesson might be to employ new catalysts not only with monofunctional model compounds but also to test functional group tolerance and-as has already been done in some cases - to apply the catalysts to the total synthesis of relevant target molecules.

\section{References}

1 For an overview on the significance of catalysis in fine chemicals production, see Blaser, H.U. and Studer, M. (1999) Applied Catalysis A: General, 189, 191.

2 For an overview of the application of enantioselective catalysis in fine chemicals production, see (a) Blaser, H.U., Spindler, F. and Studer, M. (2002) Applied Catalysis A: General, 221, 119; (b) Blaser, H.U. and Schmidt, E. (eds) (2003) Large-Scale Asymmetric Catalysis, WileyVCH Verlag $\mathrm{GmbH}$, Weinheim, p. 1.

3 For an assessment of enantioselective catalysis from an industrial point of view, see Blaser, H.U., Pugin, B. and Spindler, F. (2005). Journal of Molecular Catalysis A-Chemical, 231, 1.

4 For a recent review, see Blaser, H.U. and Spindler, F. (2007) Handbook of Homogeneous Hydrogenation (eds J.G. de
Vries and C.J. Elsevier), Wiley-VCH Verlag GmbH, p. 1193.

5 Imamoto, T., Iwadate, N. and Yoshida, K. (2006) Organic Letters, 8, 2289.

6 Xiao, D. and Zhang, X. (2001) Angewandte Chemie-International Edition, 40, 3425.

7 Cheemala, M.N. and Knochel, P. (2007) Organic Letters, 9, 3089.

8 Moessner, C. and Bolm, C. (2005) Angewandte Chemie-International Edition, 44, 7564.

9 Zhu, S.-F., Xie, J.-B., Zhang, Y.-Z., Li, S. and Zhou, Q.-L. (2006) Journal of the American Chemical Society, 128, 12886.

10 Blaser, H.U., Buser, H.P., Häusel, R., Jalett, H.P. and Spindler, F. (2001) Journal of Organometallic Chemistry, 621, 34.

11 Reetz, M.T. and Bondarev, O. (2007) Angewandte Chemie - International Edition, 46, 4523. 
12 Yamagata, T., Tadaoka, H., Nagata, M., Hirao, T., Kataoka, Y., Ratovelomana, V., Genêt, J.P. and Mashima, K. (2006) Organometallics, 25, 2505.

13 Morimoto, T., Suzuki, N. and Achiwa, K. (1998) Tetrahedron: Asymmetry, 9, 183.

14 Zhu, G. and Zhang, X. (1998) Tetrahedron: Asymmetry, 9, 2415.

15 Morimoto, T., Suzuki, N. and Achiwa, K. (1996) Heterocycles, 43, 2557.

16 Reetz, M.T. and Li, X. (2006) Chemical Communications, 2159.

17 Wang, W.-B., Lu, S.-M., Yang, P.-Y., Han, X.-W. and Zhou, Y.-G. (2003) Journal of the American Chemical Society, 125, 10536.

18 Lu, S.-M., Han, X.-W. and Zhou, Y.-G. (2004) Advanced Synthesis Catalysis, 346, 905.

19 Xu, L., Lam, K.H., Ji, J., Wu, J., Fan, Q.-H., Lo, W.-H. and Chan, A.S.C. (2005) Chemical Communications, 1390.

20 Lam, K.H., Xu, L., Feng, L., Fan, Q.-H., Lam, F.L., Lo, W.-G. and Chan, A.S.C. (2005) Advanced Synthesis Catalysis, 347, 1755.

21 Tang, W.-J., Zhu, S.-F., Xu, L.-J., Zhou, Q.-L., Fan, Q.-H., Fan, Q.-H., Zhou, H.-F., Lam, K. and Chan, A.S.C. (2007) Chemical Communications, 613.

22 Solinas, M., Pfaltz, A., Cozzi, P.G. and Leitner, W. (2004) Journal of the American Chemical Society, 126, 16142.

23 Fuchs, R. (1997) E P 0803502 A2, assigned to Lonza AG.

24 Blaser, H.U., Buser, H.P., Coers, K., Hanreich, R., Jalett, H.P., Jelsch, E., Pugin, B., Schneider, H.D., Spindler, F. and Wegmann, A. (1999) Chimia, 53 , 275.

25 Blaser, H.U. (2002) Advanced Synthesis Catalysis, 344, 17.

26 Hofer, R. (2005) Chimia, 59, 10.

27 Blaser, H.U., Buser, H.P., Jalett, H.P., Pugin, B. and Spindler, F. (1999) Synlett, 867.

28 Pugin, B., Landert, H., Spindler, F. and Blaser, H.U. (2002) Advanced Synthesis Catalysis, 344, 974
29 Imwinkelried, R. (1997) Chimia, 51, 300.

30 Satoh, K., Inenaga, M. and Kanai, K. (1998) Tetrahedron: Asymmetry, 9, 2657.

31 de Vries, J.G. and Elsevier, C.J. (2007) Handbook of Homogeneous Hydrogenation, Wiley-VCH Verlag GmbH, p. 1586.

32 (a) Crabtree, R.H., Felkin, H., FillebeenKhan, T. and Morris, G.E. (1979) Journal of Organometallic Chemistry, 168, 183;

(b) Crabtree, R.H. (1979) Accounts of Chemical Research, 12, 331.

33 Lightfoot, A., Schnider, P. and Pfaltz, A. (1998) Angewandte Chemie-International Edition, 37, 2897.

34 For a recent update, see Roseblade, S.J. and Pfaltz A. (2007) Accounts of Chemical Research, 40, 1402-11.

35 Cui, X. and Burgess, K. (2005) Chemical Reviews, 105, 3272.

36 Källström, K., Munslow, I. and Andersson, P.G. (2006) Chemistry-A European Journal, 12, 3194.

37 Yue, T.-Y. and Nugent, W.A. (2002) Journal of the American Chemical Society, 124, 13692.

38 Bell, S., Wüstenberg, B., Kaiser, S., Menges, F., Netscher, T. and Pfaltz, A. (2006) Science, 311, 642.

39 Trost, B.M. and Lee, C. (2000) Catalytic Asymmetric Synthesis, 2nd edn (ed. I. Ojima), Wiley-VCH Verlag GmbH, New York, p. 593.

40 For a recent overview, see Helmchen, G., Dahnz, A., Dübon, P., Schelwies, M. and Weihofen, R. (2007) Chemical Communications, 675.

41 For an update, see Takeuchi, R., Kezuka, S. (2006) Synthesis, 3349.

42 Auer, E., Gross, M., Panster, P. and Takemoto, K. (2001) Catalysis Today, 65, 31.

43 Auer, E., Freund, A., Gross, M., Hartung, R. and Panster, P. (1998) Catalysis of Organic Reactions (Dekker), 75, 551.

44 Atzrodt, J., Derdau, V., Fey, T. and Zimmermann, J. (2007) Angewandte Chemie - International Edition, 46, 7744. 